\title{
Angelica Sinensis Root Extract
}

National Cancer Institute

\section{Source}

National Cancer Institute. Angelica Sinensis Root Extract. NCI Thesaurus. Code C60817.

An herbal extract derived from the root of the plant Angelica sinensis with possible antiinflammatory, antispasmodic, vasodilatory, estrogenic, and antitumor activities. Angelica sinensis contains volatile oils, including safrole, isosafrole, and n-butylphthalide; coumarin derivatives, including psoralens, bergapten, osthol, imperatorin, and oxypeucedanin; and ferulic acid. The coumarin derivatives in this agent may vasodilate and relax smooth muscle and may exhibit additive anticoagulant effects. Ferulic acid, a phenolic phytochemical present in plant cell walls, may neutralize free radicals such as reactive oxygen species. In addition, Ang elica sinensis extract has been shown to inhibit the growth and induce apoptosis of glioblastoma mutltiforme brain tumor cells through p53-dependent and p53-independent pathways. 